\title{
Flow cytometric analysis of the CD4+ TCR V $\beta$ repertoire in the peripheral blood of children with type 1 diabetes mellitus, systemic lupus erythematosus and age-matched healthy controls
}

\author{
Flora Tzifi ${ }^{1}{ }^{*}$, Maria Kanariou ${ }^{2 \dagger}$, Marianna Tzanoudaki ${ }^{2}$, Constantinos Mihas ${ }^{3}$, Evangelia Paschali ${ }^{2}$, \\ George Chrousos $^{1}$ and Christina Kanaka-Gantenbein ${ }^{1+}$
}

\begin{abstract}
Background: Data regarding the quantitative expression of TCR V $\beta$ subpopulations in children with autoimmune diseases provided interesting and sometimes conflicting results. The aim of the present study was to assess by comparative flow cytometric analysis the peripheral blood CD4+ TCR V $\beta$ repertoire of children with an organ-specific autoimmune disorder, such as type 1 diabetes mellitus (T1DM), in comparison to children with a systemic autoimmune disease, such as Systemic Lupus Erythematosus (SLE) in comparison to healthy age-matched controls of the same ethnic origin. The CD4+ TCR V $\beta$ repertoire was analysed by flow cytometry in three groups of participants: a) fifteen newly diagnosed children with T1DM (mean age: $9.2 \pm 4.78$ years old), b) nine newly diagnosed children with SLE, positive for ANA and anti-dsDNA, prior to treatment (mean age: $12.8 \pm 1.76$ years old) and c) 31 healthy age-matched controls (mean age: $6.58 \pm 3.65$ years old), all of Hellenic origin.
\end{abstract}

Results: CD4 + TCR V $\beta$ abnormalities ( \pm 3SD of controls) were observed mainly in SLE patients. Statistical analysis revealed that the CD4 + V $\beta 4$ chain was significantly increased in patients with T1DM $(p<0.001)$, whereas CD4 + V $\beta 16$ one was significantly increased in SLE patients $(p<0.001)$ compared to controls.

Conclusions: $C D 4+V \beta 4$ and CD4 + V 16 chains could be possibly involved in the cascade of events precipitating the pathogenesis of T1DM and SLE in children, respectively.

Keywords: TCR V $\beta$ repertoire, Flow cytometry, T1DM, SLE, Children

\section{Background}

Autoimmunity involves complex pathophysiological processes; however, no comprehensive model of inflammatory induction has been unraveled as yet. Genetic and environmental immunologic factors, several hormones and stress have been implicated in the pathogenesis of autoimmune disorders [1-4]. Moreover, the T cell

\footnotetext{
*Correspondence: fltzifi@med.uoa.gr

${ }^{\dagger}$ Equal contributors

${ }^{1}$ First Department of Pediatrics, Division of Endocrinology, Diabetes and Metabolism, National Kapodistrian University of Athens, "Aghia Sophia" Children's Hospital, Thivon \& Papadiamantopoulou street, 11527 Athens, Greece

${ }^{2}$ Department of Immunology \& Histocompatibility, Specific Center \& Referral Center for Primary Immunodeficiencies - Paediatric Immunology, "Aghia Sophia" Children's Hospital, Athens, Greece

Full list of author information is available at the end of the article
}

receptor (TCR), with its extended repertoire derived from somatic recombination mechanisms, plays a potential role in human autoimmune disease [5]. Animal and human genetic studies have shown that skewing of TCR V $\beta$ repertoire is a characteristic feature of some autoimmune disorders although still controversy exists on that issue $[6,7]$.

TCR V $\beta$ repertoire is assessed with two methodologies, CDR3 spectratyping, which is a genetic assay that provides mainly qualitative information about TCR V $\beta$ clonality $[8,9]$, and flow cytometry analysis, which provides a quantitative assessment of TCR V $\beta$ clones and is well established in the clinical setting $[10,11]$. In $\mathrm{T}$ cellmediated organ-specific autoimmune diseases, such as type 1 diabetes (T1DM), TCR V $\beta$ repertoire analysis,

\section{() Biomed Central}


using both spectratyping and flow cytometry, produced conflicting findings $[12,13]$. In systemic autoimmune diseases, like Systemic Lupus Erythematosus (SLE), TCR V $\beta$ analysis has been conducted in adult populations using the spectratyping method and a marked oligoclonality of the TCR V $\beta$ repertoire has been reported, which is more prominent in patients with active disease $[14,15]$. It is likely that children with SLE display a similar phenotype, although no data exist regarding the expression of the $V \beta$ chains in the pediatric population. The marked skewing of the TCR V $\beta$ repertoire observed in some SLE patients has not been found in T1DM patients, although a comparative study in a pediatric population between an organ-specific disease, such as T1DM, and a systemic autoimmune one, such as SLE, to our knowledge, has not been conducted as yet.

The aim of this study was to compare the peripheral blood CD4+ TCR V $\beta$ repertoire in children with T1DM and SLE, in comparison to healthy age-matched controls of the same ethnic origin with the use of the flow cytometry assay.

\section{Results}

\section{a) Healthy children}

Complete blood count values, immunoglobulin levels and lymphocyte subpopulation counts were normal in all healthy children. Autoantibodies, either SLE-specific or diabetes speficic (ANA, anti-dsDNA, ICA), were evaluated and they were negative in all controls tested. There was an unavoidable male preponderance in the tested children (boys: $80.6 \%$ ), due to the higher frequency of anatomical abnormalities needing surgical reconstruction in boys.

Mean values and standard deviations (SD) of each distinct $\mathrm{V} \beta$ family percentage on $\mathrm{CD} 4+$ lymphocytes of the 31 studied children are shown in Table 1. TCR V $\beta$ usage appears to be non-random varying from low values of $0.0 \%$ for $\mathrm{V} \beta 4$ and $\mathrm{V} \beta 7.2$ to high values of $12.8 \%$ for $\mathrm{V} \beta 2$. Additionally, in one individual the value of the $V \beta 7.2$ chain was $0.0 \%$. The known polymorphism (null expression) in V 320 subfamily was not detected in the population tested.

The increased/decreased usage of a V $\beta$ subfamily has arbitrarily been defined as mean value \pm 2 or 3 standard deviations (mean value is the one derived from the control sample of the present study) [10,11]. Of the children tested, 16 individuals had increased usage (expressed as mean value +2 or $3 \mathrm{SD}$ ) of one or more $\mathrm{V} \beta$ lymphocyte populations and these findings concerned different $\mathrm{V} \beta$ chains in each subject. Seven children had an increased usage of mean value $+2 \mathrm{SD}$ and nine an increased usage of mean value $+3 \mathrm{SD}$. Of these 16 subjects, 11 controls presented with an increased usage in only one chain (V $\beta 1, \mathrm{~V} \beta 3$, V $\beta 5.1, \mathrm{~V} \beta 5.2, \mathrm{~V} \beta 5.3, \mathrm{~V} \beta 7.1, \mathrm{~V} \beta 12, \mathrm{~V} \beta 14, \mathrm{~V} \beta 16$, $\mathrm{V} \beta 20, \mathrm{~V} \beta 22), 4$ controls had increased usage in two $V \beta$ subpopulations (V $\beta 4-\mathrm{V} \beta 2$ 2, V $\beta 5.1-\mathrm{V} \beta 21.3$, V $\beta 13.1-\mathrm{V} \beta 13.6$,
Table 1 CD4 + V $\beta$ repertoire usage in healthy children

\begin{tabular}{|c|c|c|c|c|}
\hline Vb subfamily & Mean percentage & $\min (\%)$ & $\max (\%)$ & SD \\
\hline Vb1 & 3.21 & 1.8 & 4.9 & .66 \\
\hline Vb2 & 7.86 & 4 & 12.8 & 2.33 \\
\hline Vb3 & 4.23 & 1 & 8.5 & 2.22 \\
\hline Vb4 & .76 & .0 & 2.3 & .58 \\
\hline Vb5.1 & 4.43 & 1.8 & 6.9 & 1.48 \\
\hline Vb5.2 & 1.39 & .5 & 4.8 & .97 \\
\hline Vb5.3 & 1.69 & 6 & 3.5 & .73 \\
\hline Vb7.1 & 1.85 & .4 & 4.1 & .89 \\
\hline Vb7.2 & 1.71 & .0 & 4.9 & 1.07 \\
\hline Vb8 & 3.95 & 2 & 6.4 & 1.02 \\
\hline Vb9 & 2.90 & .8 & 12.6 & 2.13 \\
\hline Vb11 & 1.49 & .4 & 2.9 & .70 \\
\hline Vb12 & 4.44 & 1.6 & 9.7 & 1.65 \\
\hline Vb13.1 & 4.23 & 2.1 & 7.4 & 1.35 \\
\hline Vb13.2 & 2.58 & .2 & 6.8 & 1.42 \\
\hline Vb13.6 & 1.86 & .8 & 3.5 & .61 \\
\hline Vb14 & 4.00 & 1.4 & 9.6 & 1.78 \\
\hline Vb16 & 2.03 & 6 & 5.1 & .99 \\
\hline Vb17 & 3.88 & .1 & 5.4 & 1.33 \\
\hline Vb18 & 1.34 & .2 & 3.9 & .90 \\
\hline Vb20 & 4.08 & 1.2 & 7.6 & 1.75 \\
\hline Vb21.3 & 2.47 & .7 & 3.6 & .71 \\
\hline Vb22 & 2.84 & .7 & 7.5 & 1.26 \\
\hline Vb23 & 1.17 & .2 & 4 & .90 \\
\hline
\end{tabular}

TOTAL: 70.39 (CD4+).

CD4 + TCR V $\beta$ repertoire usage in 31 healthy Greek Children. Minimum (min) and maximum (max) values obtained, as well as the mean percentages of the 24 CD4+ TCR V $\beta$ chains are displayed. SD standard deviation.

$\mathrm{V} \beta 7.2-\mathrm{V} \beta 13.2$ ) and one control in five ones (V $\beta 5.2, \mathrm{~V} \beta 7.4$, $\mathrm{V} \beta 8, \mathrm{~V} \beta 9$, V $\beta 18$ ) (Figure 1). No discrepancies were noticed in the $V \beta 11$ and $V \beta 17$ chains.

Enrolled infants and children were separated into three age groups, which were compared in order to find out possible differences in $V \beta$ expression at different age groups. Table 2 displays median values and interquartile range of the CD4+ TCR V $\beta$ repertoire in the aforementioned subgroups as well as in the total population of the study. Statistical analysis revealed no significant difference for each of the 24 TCR V $\beta$ subfamilies in the CD4+ T lymphocytes.

\section{b) T1DM children}

Assessment of the CD4+ TCR V $\beta$ repertoire was performed in two ways: a) $\mathrm{V} \beta$ repertoire of each T1DM patient was compared with the $\mathrm{V} \beta$ mean values of the control group and b) statistical analysis was performed, 


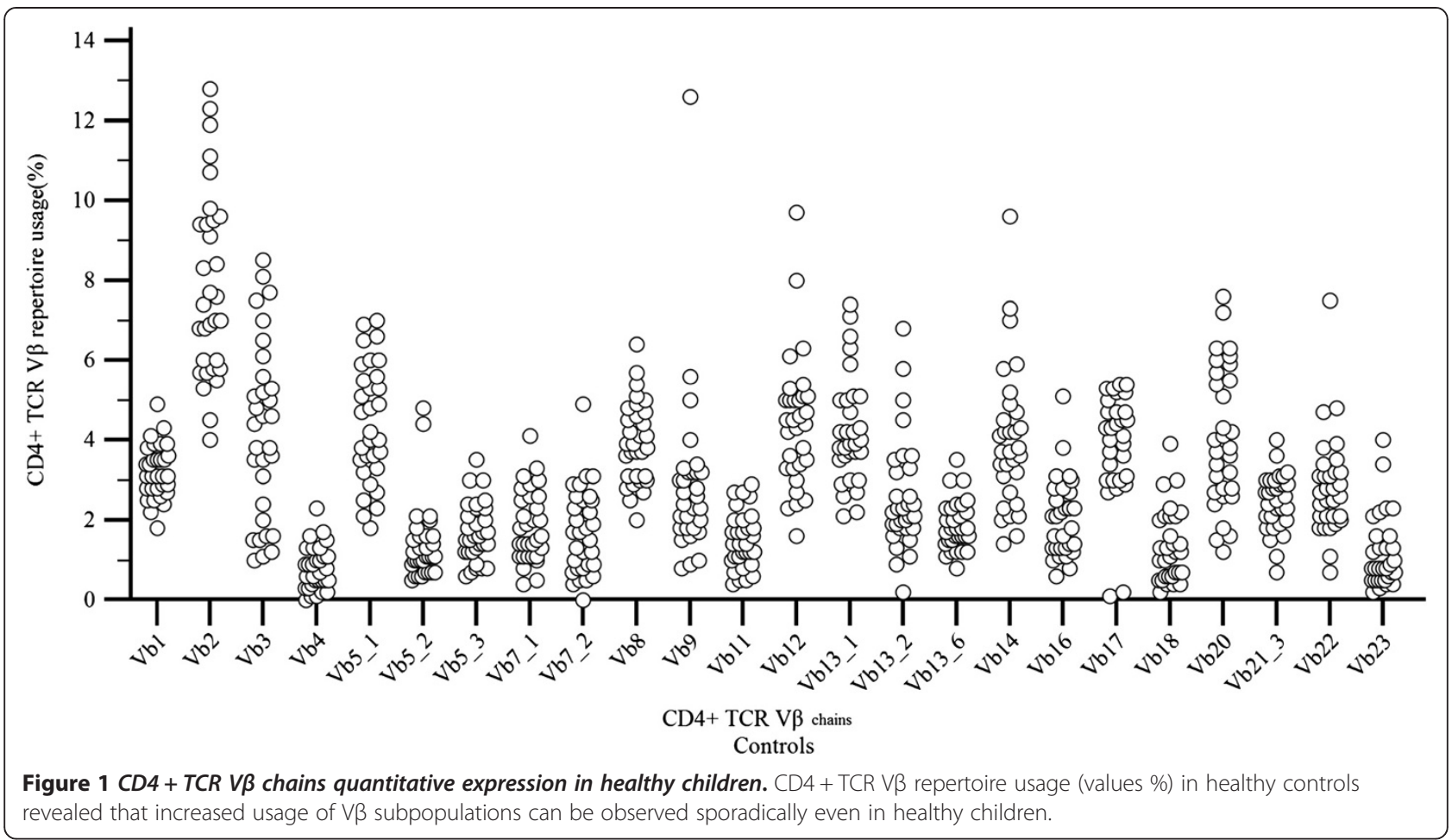

in order to detect the presence of $\mathrm{CD} 4+\mathrm{V} \beta$ lymphocyte clones in the group of T1DM patients with different quantitative expression in comparison to the control group.

The increased/decreased usage of a V $\beta$ subfamily was defined as control mean value \pm 2 or 3 standard deviations $[10,11]$. Five patients $(33 \%)$ presented no abnormalities in all $\mathrm{CD} 4+\mathrm{V} \beta$ chains values when compared to controls (Table 3, Figure 2). One T1DM patient had decreased usage of V $\beta 14$ (0.7\%, mean value: $4.00 \pm 1.78)$ and in another one $\mathrm{V} \beta 20$ value was $0.1 \%$ (mean value: $4.08 \pm 1.75$ ). None of the healthy individuals had such low usage of these $V \beta$ chains. Increased usage of several $\mathrm{CD} 4+\mathrm{V} \beta$ chains $(\mathrm{V} \beta 3, \mathrm{~V} \beta 4, \mathrm{~V} \beta 5.1, \mathrm{~V} \beta 5.3, \mathrm{~V} \beta 8, \mathrm{~V} \beta 11$, $\mathrm{V} \beta 18, \mathrm{~V} \beta 16$ and $\mathrm{V} \beta 21.3)$ was identified sporadically in T1DM patients. With the exception of V $\beta 11$ chain, increased usage of the mentioned $\mathrm{V} \beta$ subpopulations were also found in healthy individuals. Although the CD4+ V 84 lymphocyte population increased usage was found in 5 T1DM patients when compared to the mean value of controls, statistical analysis showed a significant difference between the two groups $(\mathrm{p}<0.001)$ concerning the CD4+Vß4 subfamily (Table 4, Figure 3 ). This is expected, since values of the controls ranged between $0.0 \%$ and $2.1 \%$ while T1DM values ranged from $0.6 \%$ to $3.3 \%$. It should be mentioned that 17 healthy children had values of the $\mathrm{CD} 4+\mathrm{V} \beta 4$ chain $<1 \%$ and $12 \mathrm{~T} 1 \mathrm{DM}$ children had values $>1 \%$ (Figure 4 ). Taking into account the very low number of $\mathrm{CD} 4+\mathrm{V} \beta 4$ cells analyzed and that the maximum coefficient of variation (CV) was $20 \%$, statistical analysis was adjusted to this CV. As shown in Table 5, the differences remained significant even after "narrowing" the mean values, adjusting for a $20 \%$ difference in the mean values of our measurements.

\section{c) SLE children}

In the SLE group, skewing in CD $4+\mathrm{V} \beta$ subpopulations was detected in the majority of patients when compared to healthy individuals. In contrast to healthy children and T1DM patients, which presented with a similar CD $4+$ TCR V $\beta$ repertoire pattern, 7 of the 9 SLE children tested displayed concurrently marked increased (mean value $\pm 3 \mathrm{SD}$ ) and decreased usage (with even values of $0.0 \%$ ) of several CD4 + V $\beta$ subpopulations. This was noteworthy in one SLE patient who displayed increased usage of the $\mathrm{CD} 4+\mathrm{V} \beta 12$ (9.44\%), $\mathrm{V} \beta 16$ (5.6\%) and $\mathrm{V} \beta 20$ (9.17\%) and a decreased one of $\mathrm{V} \beta 2(2.83 \%)$ and $\mathrm{V} \beta 5.1$ (0.12\%) chains and in another one patient with high values of $\mathrm{CD} 4+\mathrm{V} \beta 3$ (9\%), $\mathrm{V} \beta 12$ (14.2\%) and $\mathrm{V} \beta 16$ (7.3\%) chains and very low values of $\mathrm{CD} 4+\mathrm{V} \beta 2(0.2 \%), \mathrm{V} \beta 5.2(0.2 \%)$, V $\beta 7.1(0.1 \%)$ and V $\beta 22(0.3 \%)$ (Table 6, Figure 5). Markedly low values were found in the following $C D 4+V \beta$ chains: $\mathrm{V} \beta 2$ (in 2 patients), $\mathrm{V} \beta 22$ (in 2 patients), $\mathrm{V} \beta 5.1$, $\mathrm{V} \beta 5.2, \mathrm{~V} \beta 7.1, \mathrm{~V} \beta 8, \mathrm{~V} \beta 13.6$, and $\mathrm{V} \beta 18$. The $\mathrm{CD} 4+\mathrm{V} \beta 4$ subpopulation had values of $0.0 \%$ in three SLE patients. However, this finding, as previously mentioned, was noticed in healthy children as well. Increased usage of $\mathrm{V} \beta 16$ was found in 5, of $\mathrm{V} \beta 4$ in 2, of $\mathrm{V} \beta 20$ in 2 and of $\mathrm{V} \beta 12$ in 
Table 2 TCR $V \beta$ repertoire usage by age groups

\begin{tabular}{|c|c|c|c|c|c|c|c|c|c|c|c|c|}
\hline \multirow{3}{*}{$\begin{array}{c}\mathrm{V} \beta \text { repertoire } \\
\text { usage }\end{array}$} & \multicolumn{9}{|c|}{ Age categories } & & & \multirow[b]{3}{*}{$\mathrm{p}$ (overall) } \\
\hline & \multicolumn{2}{|c|}{18 months -4 years } & \multirow[b]{2}{*}{$\mathrm{p}(18 \mathrm{~m}-4 / 5-9) \dagger$} & \multicolumn{2}{|c|}{ 5-9 years } & \multirow[b]{2}{*}{$p(5-9 / 10-14)$} & \multicolumn{2}{|c|}{$10-14$ years } & \multirow[b]{2}{*}{$p(18 m-4 / 10-14)$} & \multicolumn{2}{|c|}{ Total } & \\
\hline & Median & $\mathrm{IQR}^{*}$ & & Median & $\mathrm{IQR}^{*}$ & & Median & $\mathrm{IQR}^{*}$ & & Median & $\mathrm{IQR}^{*}$ & \\
\hline VB3 & 4.70 & 3.10 & .080 & 3.35 & 2.90 & .121 & 5.20 & 2.60 & .831 & 4.40 & 3.60 & .156 \\
\hline VB5.3 & 1.50 & .70 & .692 & 1.35 & .90 & .033 & 2.30 & .90 & .059 & 1.60 & 1.10 & .068 \\
\hline VB7.1 & 1.50 & .85 & .643 & 1.25 & .90 & .022 & 2.60 & 1.20 & .050 & 1.60 & 1.50 & .048 \\
\hline$V \beta 16$ & 1.70 & 1.10 & .972 & 2.10 & 1.00 & .248 & 2.50 & 1.40 & .319 & 1.95 & 1.40 & .472 \\
\hline Vß9 & 2.35 & 1.30 & .915 & 2.70 & 1.60 & .825 & 2.60 & 1.40 & .943 & 2.50 & 1.40 & .984 \\
\hline$V \beta 17$ & 4.05 & 1.85 & .695 & 3.90 & 1.70 & .690 & 4.30 & 1.80 & .337 & 4.20 & 1.70 & .652 \\
\hline$V \beta 20$ & 3.35 & 1.70 & .339 & 4.10 & 3.10 & .838 & 5.10 & 2.30 & .145 & 3.80 & 3.00 & .346 \\
\hline$V \beta 18$ & .85 & .90 & .427 & 1.15 & .80 & .093 & 2.10 & 1.20 & .027 & 1.20 & 1.50 & .063 \\
\hline VB5.1 & 3.85 & 1.65 & .448 & 4.85 & 3.00 & .935 & 4.00 & 2.80 & .670 & 4.20 & 2.30 & .767 \\
\hline V $\beta 8$ & 4.00 & 1.30 & .741 & 4.00 & 1.80 & .236 & 3.70 & 1.40 & .374 & 3.90 & 1.60 & .472 \\
\hline$V \beta 13.1$ & 3.90 & 1.30 & .692 & 3.75 & 2.10 & .595 & 4.20 & 1.10 & .859 & 3.90 & 1.50 & .856 \\
\hline$V \beta 13.6$ & 1.55 & .60 & .128 & 1.85 & .70 & .594 & 2.10 & .50 & .058 & 1.80 & .80 & .116 \\
\hline$V \beta 12$ & 4.70 & 1.65 & .717 & 4.50 & 2.10 & .462 & 4.20 & 2.50 & .125 & 4.50 & 1.80 & .367 \\
\hline VB5.2 & 1.05 & .90 & .643 & 1.10 & .50 & .712 & 1.20 & .90 & .617 & 1.10 & .90 & .824 \\
\hline$V \beta 2$ & 7.90 & 3.25 & .448 & 6.95 & 3.80 & .513 & 7.60 & 3.10 & .722 & 7.40 & 3.70 & .688 \\
\hline$V \beta 21.3$ & 2.35 & .95 & .222 & 2.65 & 1.00 & .967 & 2.80 & .70 & .319 & 2.60 & 1.00 & .418 \\
\hline$V \beta 23$ & .80 & .65 & .740 & .75 & 1.10 & .189 & 1.30 & 1.50 & .074 & .80 & 1.10 & .188 \\
\hline VB1 & 3.10 & .55 & .425 & 3.25 & .70 & .594 & 3.50 & 1.10 & .198 & 3.10 & .80 & .414 \\
\hline$V \beta 14$ & 4.20 & 1.75 & .306 & 3.50 & 1.90 & .967 & 3.70 & 1.50 & .226 & 3.70 & 2.00 & .418 \\
\hline$V \beta 11$ & 1.20 & .95 & .921 & 1.50 & .90 & .190 & 1.80 & 1.40 & .212 & 1.40 & 1.00 & .342 \\
\hline$V \beta 22$ & 2.70 & 1.20 & .766 & 2.55 & 1.10 & .165 & 3.10 & 1.40 & .269 & 2.70 & 1.10 & .348 \\
\hline$V \beta 7.2$ & 1.35 & 1.70 & .113 & 2.25 & 1.90 & .487 & 1.70 & 1.10 & .355 & 1.70 & 1.70 & .261 \\
\hline$V \beta 13.2$ & 1.85 & .95 & .129 & 2.80 & 1.80 & 1.000 & 2.40 & .30 & .042 & 2.20 & 1.50 & .110 \\
\hline V $\beta 4$ & .85 & .65 & .741 & .70 & .70 & .411 & .50 & .90 & .238 & .70 & .80 & .484 \\
\hline
\end{tabular}

No age-related differences in CD4 + V $\beta$ expression were found among the three age groups of healthy Greek children studied.

* $I Q R$ Interquartile range $\left(75^{\text {th }}-25^{\text {th }}\right.$ percentile).

† The numbers in brackets indicate the two age groups that were used for the comparison with the corresponding p-value.

2 patients. It should be mentioned, though, that there were two SLE patients with a normal repertoire at initial diagnosis. When statistical analysis was performed in order to compare the CD4 $+\mathrm{V} \beta$ expression between SLE and healthy children, significant differences in TCR V $\beta$ quantitative expression were noticed only for the $\mathrm{V} \beta 16$ chain $(\mathrm{p}<0.001)$ (Table 3, Figure 6). This was expected, since five SLE patients presented with higher values of the $\mathrm{CD} 4+\mathrm{V} \beta 16$ chain than those of the control group (mean value $+3 \mathrm{SD}$ ) (Figure 7 ). Only one healthy individual presented an increased usage of $\mathrm{CD} 4+\mathrm{V} \beta 16$, but he displayed no other discrepancies of the rest $\mathrm{CD} 4+$ $\mathrm{V} \beta$ subfamilies.

\section{d) Findings of $T$ lymphocyte populations by flow cytometric analysis}

The basic immunophenotyping findings of the T1DM and SLE groups, when compared to controls, were as follows: a) Increased expression of CD69 molecule in two SLE patients and in one T1DM patient, b) elevated percentage of the $\mathrm{CD} 3+\mathrm{TCR} \gamma \delta$ lymphocyte population (20\%) in two SLE patients, c) increased expression of the HLA-DR + cells in 2 of the nine SLE children tested and d) absolute number of B lymphocytes (CD19+) beyond normal values in one SLE and in one T1DM patient. No difference in the CD5 + CD19+ expression was noticed among the three groups and the values (\%) of the $\mathrm{CD} 5+\mathrm{CD} 19+$ populations ranged between 0.1 and $1.2 \%$ in all individuals tested.

\section{Discussion}

Flow cytometric analysis of the CD $4+\mathrm{TCR} V \beta$ repertoire performed in three different groups of children of Greek origin, healthy, T1DM and SLE ones, provided results similar to previous published studies, but with some differences. 
Table 3 CD4 + V $\beta$ chains usage in T1DM children

\begin{tabular}{|c|c|c|}
\hline $\begin{array}{l}\text { T1DM } \\
\text { children }\end{array}$ & $\begin{array}{c}\text { CD4+ TCR V } \beta \text { Increased } \\
\text { usage }\end{array}$ & $\begin{array}{c}\text { CD4 + TCR V } \beta \text { Decreased } \\
\text { usage }\end{array}$ \\
\hline Patient 1 & VB5.1 (7.3\%, M + 2SD) & None \\
\hline Patient 2 & VB5.3 (5.8\%, M + 3SD) & None \\
\hline \multirow[t]{4}{*}{ Patient 3} & $V \beta 16(5 \%, M+3 S D)$ & None \\
\hline & VB5.1 (7.5\%, M + 2SD) & \\
\hline & $V \beta 8(6.5 \%, M+2 S D)$ & \\
\hline & VB21.3 (4.1\%, M + 2SD) & \\
\hline Patient 4 & None & None \\
\hline \multirow[t]{3}{*}{ Patient 5} & $V \beta 16(5.5 \%, M+3 S D)$ & VB14 (0.7\%, M-2SD) \\
\hline & $V \beta 18$ (4.1\%, M + 3SD) & \\
\hline & $V \beta 11(3.1 \%, M+2 S D)$ & \\
\hline Patient 6 & None & None \\
\hline Patient 7 & None & None \\
\hline Patient 8 & VB3 (11.2\%, M + 3SD) & None \\
\hline Patient 9 & $V \beta 4(2.6 \%, M+3 S D)$ & None \\
\hline Patient 10 & None & None \\
\hline Patient 11 & $V \beta 4(2.3 \%, M+2 S D)$ & None \\
\hline Patient 12 & $V \beta 4(2.1 \%, M+2 S D)$ & None \\
\hline Patient 13 & None & None \\
\hline Patient 14 & $V \beta 4(2.2 \%, M+2 S D)$ & None \\
\hline \multirow[t]{2}{*}{ Patient 15} & VB5.1 (9.1\%, M + 3SD) & VB20 (0.5\%, M-2SD) \\
\hline & $V \beta 4(3.3 \%, M+3 S D)$ & \\
\hline
\end{tabular}

CD4 + TCR V $\beta$ repertoire observed in T1DM patients in comparison to controls was similar. Low usage of the $V \beta$ chains is rarely found in patients with T1DM.
As far as healthy children are concerned, the results of this study support the non-random usage of TCR V $\beta$ subfamilies in Greek children, as observed in previous studies on normal adults and children [11,16,17]. There is also no statistical difference in $\mathrm{T}$ cell repertoire among the three pediatric age groups studied and this is in accordance to another pediatric population studied in the United Kingdom [11]. Many healthy individuals had also sporadically increased expression of $\mathrm{CD} 4+\mathrm{V} \beta$ chains as previously shown $[11,16,17]$. To our knowledge, analysis of the $\mathrm{CD} 4+\mathrm{V} \beta$ repertoire expression pattern in Greek adults has not been conducted so far, so comparison with values of adults of the same ethnic origin could not be performed.

T1DM children had an almost same CD $4+\mathrm{V} \beta$ repertoire pattern with healthy individuals, with the exception of the CD4 + VB4 chain which had increased expression in T1DM patients when compared to controls. Previous studies have shown similar results, that is either no differences between the two groups [12], or increased usage of other chains like the V $\beta 7$ one $[13,18]$. Some putative explanations for the absence of consistency in the results among several studies could be the scarcity of published studies in human populations, the small size of the samples tested both in our study and others, as well as the different methodologies applied for the TCR repertoire assessment. It is still unclear though, whether the increased expression of $\mathrm{CD} 4+\mathrm{V} \beta 4$ in newly diagnosed T1DM children of Hellenic origin is a constant finding

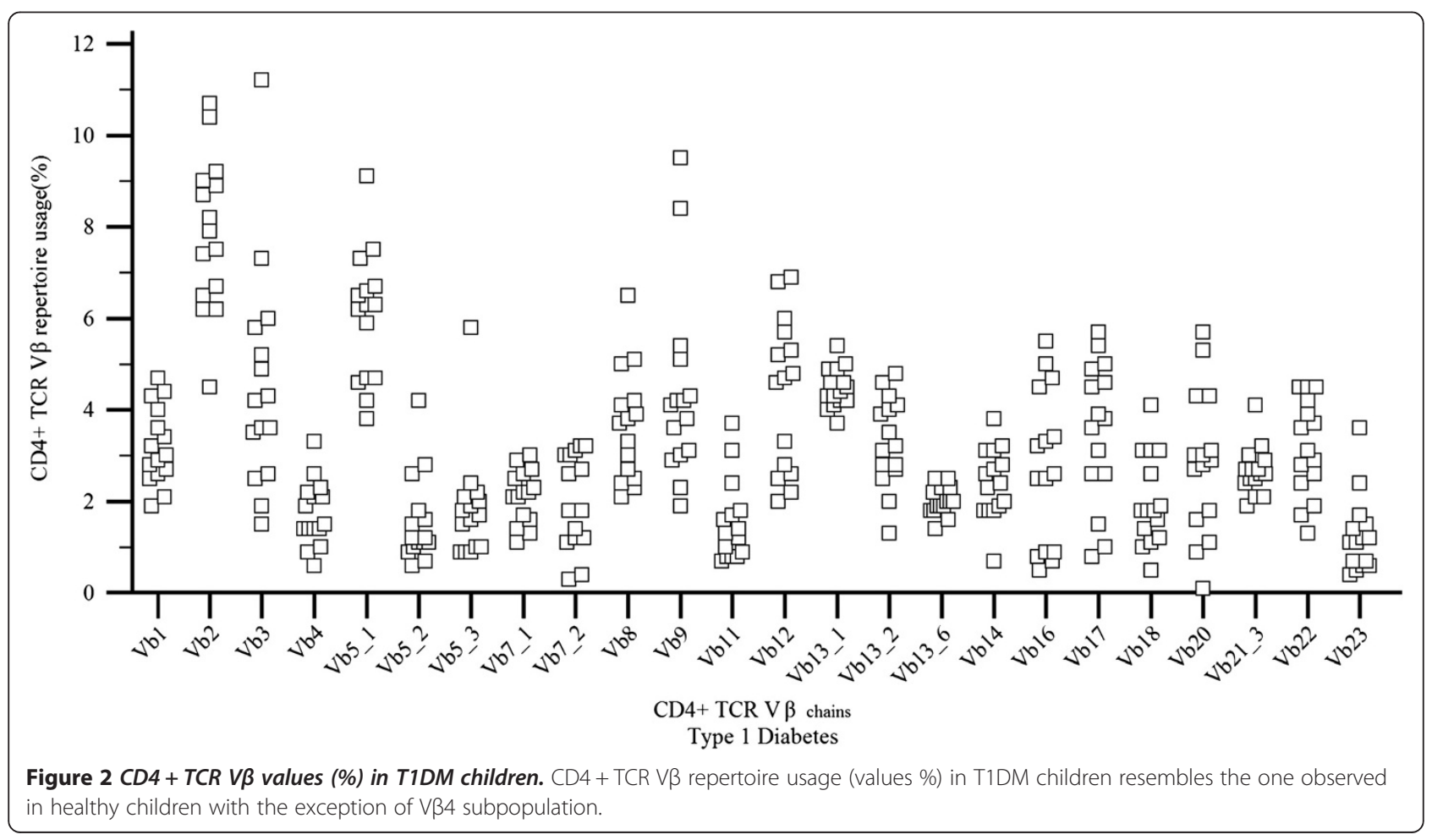


Table 4 Results of statistical analysis between T1DM children and controls and SLE children and controls

\begin{tabular}{|c|c|c|c|c|c|c|c|c|}
\hline & Groun & & & & & & & \\
\hline & Controls & & SLE & & & $1 \mathrm{DM}$ & & \\
\hline & Median & iqr & Median & ic & $p$ & Median & iqr & $p$ \\
\hline b3 & 4.40 & 3.60 & 5.60 & 2.40 & .200 & 4.20 & 3.20 & .833 \\
\hline b5.3 & 1.60 & 1.10 & 1.40 & 1.00 & .661 & 1.70 & 1.10 & .851 \\
\hline 07.1 & 1.60 & 1.50 & 1.70 & 1.40 & .475 & 2.20 & 1.00 & .181 \\
\hline Vb16 & 1.95 & 1.40 & 5.62 & 4.30 & $<.001$ & 2.60 & 3.60 & .252 \\
\hline 9 & 2.50 & 1.40 & 3.60 & 2.60 & .019 & 4.1 & 2.10 & .002 \\
\hline b17 & 4.20 & 1.70 & 2.40 & 3.26 & .029 & 3.80 & 2.30 & .515 \\
\hline 20 & 3.80 & 3.00 & 3.85 & 2.75 & .543 & 2.90 & 2.70 & .044 \\
\hline b18 & 1.20 & 1.50 & 1.00 & 1.00 & .464 & 1.80 & 1.90 & .027 \\
\hline b5.1 & 4.20 & 2.30 & 4.00 & 2.40 & .498 & 6.30 & 2.00 & .003 \\
\hline b8 & 3.90 & 1.60 & 2.80 & 2.90 & .175 & 3. & 1.70 & .302 \\
\hline /b13.1 & 3.90 & 1.50 & 5.10 & 1.10 & .067 & 4.40 & .70 & .119 \\
\hline . & 1.80 & .80 & 1. & 0 & .791 & 2. & .00 & .145 \\
\hline b12 & 4.50 & 1.80 & 6.30 & 4.64 & .013 & 4.70 & 3.10 & .879 \\
\hline 05.2 & 1.10 & .90 & 1.70 & 1.20 & .650 & 1.2 & .80 & .438 \\
\hline Vb2 & 7.40 & 3.70 & 7.00 & 4.67 & .318 & 7.90 & 2.50 & .815 \\
\hline b21.3 & 2.60 & 1.00 & 3.48 & .80 & .006 & 2.60 & .50 & .605 \\
\hline b23 & 0 & 1.10 & 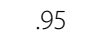 & .51 & .986 & 1.10 & .90 & .557 \\
\hline لb1 & 3.10 & .80 & 3.45 & 2.05 & .564 & 3.00 & 1.40 & .869 \\
\hline 14 & 3.70 & 2.00 & 3.35 & 3.09 & .83 & 2. & 1.30 & .001 \\
\hline Vb11 & 1.40 & 1.00 & 1.79 & 1.40 & .169 & 1.30 & 1.00 & .842 \\
\hline Vb22 & 2.70 & 1.10 & 2.10 & 2.22 & .085 & 3.10 & 1.80 & .236 \\
\hline $\mathrm{b} 7.2$ & 1.70 & 1.70 & 3.15 & 1.45 & .010 & 1.80 & 1.80 & .241 \\
\hline $\mathrm{Vb} 13.2$ & 2.20 & 1.50 & 3.25 & 1.35 & .012 & 3.20 & 1.40 & .017 \\
\hline Vb4 & .70 & .70 & 1.15 & 2.04 & .542 & 1.50 & .80 & $<.001$ \\
\hline
\end{tabular}

Statistical analysis of the CD4+ TCR V $\beta$ lymphocytes between a) SLE patients and controls, b) T1DM patients and controls. Only the V $\beta 16$ chain presented with significantly increased usage in SLE children and the V $\beta 4$ chain in T1DM ones.

in later stages of diabetes or not. Large-scale multicenter longitudinal studies are required to clarify this issue. A similar confirmed polymorphism of the TCRV20S1 gene was found in the healthy Sardinian population, but further research failed to relate this polymorphism with the high incidence of T1DM in Sardinians [19].

In contrast to T1DM patients, in SLE patients skewing of the $\mathrm{CD} 4+\mathrm{V} \beta$ repertoire is far more prominent. This finding is in accordance to previous studies published in adults $[14,15]$. CDR3 spectratyping performed in the peripheral blood of 20 adult SLE patients has shown a prominent usage of the $\mathrm{V} \beta 16$ chain among other $\mathrm{V} \beta$ subpopulations (V $\beta 2, \mathrm{~V} \beta 8, \mathrm{~V} \beta 11, \mathrm{~V} \beta 14, \mathrm{~V} \beta 19$ and $\mathrm{V} \beta 24)$ [15]. In the present study, in which flow cytometry was used, increased usage of the V $\beta 16$ chain in the CD4+ T cells of peripheral blood was found in the majority of SLE children. Higher values of other CD4+ V $\beta$ chains were also noticed in SLE children in comparison to healthy ones, but they concerned individual patients. Our results are difficult to compare with previous studies published in adults, not only because of the different methodologies used (flow cytometry versus spectratyping) or to different samples studied (children versus adults, patients at initial diagnosis versus patients under treatment) but also because of the limited number of the studies conducted in that field. Larger scale analysis in populations categorized according to age, to time of the study held (before or after treatment), to sex, to ethnicity and to methodology used could provide further insight on the role of $\mathrm{V} \beta$ repertoire not only in autoimmune disease pathogenesis but also in its clinical significance as a prognostic factor in the case of SLE.

Limitations of the present study are the limited number of the patients studied, but this is due to the rarity of lupus in children in the Greek population and to the fact that only patients upon the initial diagnosis were selected in order to avoid alterations in their immunological profile that medication could induce. Another parameter is the fact that evaluation of the $\mathrm{V} \beta$ repertoire in each patient is not influenced by the number of the patients investigated. Although genetic evaluation was not performed, all previous published studies in immune mediated diseases have showed that there are no discrepancies between the results from flow cytometric analysis and spectratyping, enhancing the reliability of flow cytometry. Finally, the CD8+V $\beta$ lymphocyte subpopulations were not analyzed, and therefore it is not known whether there are abnormalities in the repertoire of children with diabetes or lupus or not.

As far as immunophenotyping analysis is concerned, no major differences among the groups were noticed. Regarding the role of the CD5 + CD19+ population in autoimmune process, its expression was quite similar in the three groups studied. This finding is in accordance with other studies in adult SLE patients, but not with studies in T1DM patients, in whom increased expression was observed $[20,21]$.

\section{Conclusions}

This is the first comparative flow cytometric analysis between an organ-specific autoimmune disease, T1DM, and a systemic one, SLE, which underscores the importance of the TCR V $\beta$ repertoire in patients with autoimmune diseases. This study was possible because of the availability of an easily applicable method at a clinical setting, which enabled TCR V $\beta$ repertoire analysis prior to initiation of any treatment that could possibly be a confounding factor. Abnormalities of the CD4+ TCR V $\beta$ repertoire quantitative expression were observed mainly in SLE children. Low usage of certain CD4+ TCR V $\beta$ chains was also far more prominent in lupus patients. 

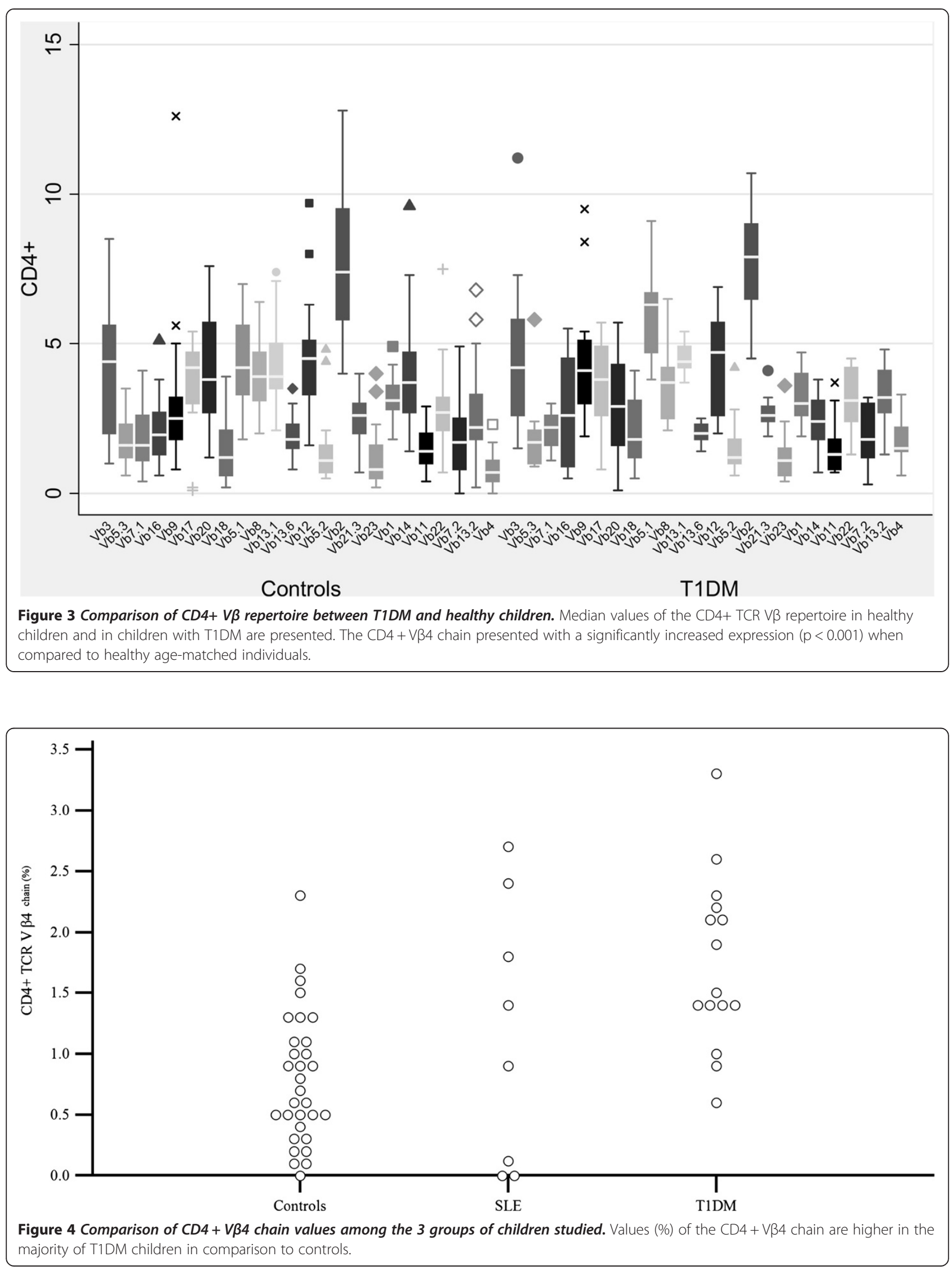
Table 5 Adjusted statistical analysis in CD4 + V $\beta 4$ chain

\begin{tabular}{|c|c|c|c|c|c|c|c|c|c|}
\hline $\mathrm{V} \beta 4$ & Group & Mean & Std. Err. & Std. Dev. & [95\% Conf. & Interval] & & & \\
\hline & Controls & 0.797 & 0.097 & 0.541 & 0.598 & 0.995 & $<.001$ & & \\
\hline & T1DM & 1.740 & 0.183 & 0.710 & 1.347 & 2.133 & & & \\
\hline \multirow[t]{3}{*}{$\mathrm{V \beta 4}$} & Group & "New" mean & & & Std. Err. & Std. Dev. & [95\% Conf. & Interval] & $\mathrm{p}$ \\
\hline & Controls & 0.956 & \multicolumn{2}{|c|}{$+20 \%$ of the original value } & 0.097 & 0.541 & 0.598 & 0.995 & 0.026 \\
\hline & T1DM & 1.392 & \multicolumn{2}{|c|}{$-20 \%$ of the original value } & 0.183 & 0.710 & 1.347 & 2.133 & \\
\hline
\end{tabular}

Adjustment of statistical analysis for the CD4 + V $\beta$ cells for a maximum CV of $20 \%$ showed that differences between healthy controls and T1DM children remained significant. CV: coefficient of variation.

Only the CD4 + TCR V $\beta 4$ and CD4 + TCR V $\beta 16$ lymphocytes were significantly increased in T1DM and SLE children, respectively. However, the potential role of these lymphocyte clones in the pathogenesis of autoimmunity remains to be clarified.

\section{Methods}

\section{Subjects}

Samples were collected from a) Fifteen newly diagnosed children with T1DM (mean age \pm SD: 9.2 year $\pm 4.78,11$ males-4 females) during their hospitalization upon diagnosis in the First Department of Pediatrics of the University of Athens in "Aghia Sophia" Children's Hospital and b) Nine patients with SLE (mean age \pm SD: 12.8 years \pm 1.76 , 3 males-6 females) upon diagnosis and prior to treatment initiation, all of Hellenic origin. Thirty one healthy Greek children (mean age \pm SD: 6.58 years $\pm 3.65,26$ males -5

Table 6 Skewing of the CD4 + V $\beta$ repertoire in SLE children

\begin{tabular}{|c|c|c|}
\hline $\begin{array}{c}\text { Patients with ANA \& } \\
\text { anti-dsDNA }\end{array}$ & $\begin{array}{c}\text { CD4+ TCR V } \beta \\
\text { increased usage }\end{array}$ & $\begin{array}{c}\text { CD4 + TCR V } \beta \\
\text { decreased usage }\end{array}$ \\
\hline Patient 1 & None & None \\
\hline Patient 2 & $V \beta 16(7.4 \%, M+3 S D)$ & None \\
\hline Patient 3 & $V \beta 4(2.4 \%, M+3 S D)$ & VB18 (0\%, M-2SD) \\
\hline \multirow[t]{2}{*}{ Patient 4} & $V \beta 16(8.2 \%, M+3 S D)$ & VB8 (0.3\%, M-3SD) \\
\hline & & VB13.6 (0\%, M-3SD) \\
\hline \multirow[t]{2}{*}{ Patient 5} & VB13.2 (7.4\%, M + 3SD) & \\
\hline & $V \beta 4(2.7 \%, M+3 S D)$ & \\
\hline \multirow[t]{3}{*}{ Patient 6} & $V \beta 16(5.6 \%, M+3 S D)$ & \multirow{3}{*}{$\begin{array}{l}V \beta 5.1(0.12 \%, M-2 S D) \\
V \beta 2(2.83 \%, M-2 S D)\end{array}$} \\
\hline & VB20 (9.17\%, M + 3SD) & \\
\hline & VB12 (9.44\%, M + 3SD) & \\
\hline Patient 7 & None & None \\
\hline \multirow[t]{2}{*}{ Patient 8} & V $\beta 16(8 \%, M+3 S D)$ & \multirow[t]{2}{*}{ V $\beta 22$ (0\%, M-2SD) } \\
\hline & $V \beta 20(7.5 \%, M+2 S D)$ & \\
\hline \multirow[t]{3}{*}{ Patient 9} & $V \beta 3(9 \%, M+2 S D)$ & \multirow{3}{*}{$\begin{array}{c}\text { VB7.1 }(0.1 \%, M-2 S D) \\
\text { VB5.2 }(0.2 \%, M-2 S D) \\
\text { V } 22(0.2 \%, M-2 S D) \\
V \beta 22(0.3 \%, M-2 S D)\end{array}$} \\
\hline & VB16 (7.3\%, M + 3SD) & \\
\hline & VB12 (14.2\%, M + 3SD) & \\
\hline
\end{tabular}

Discrepancies of the CD4+ TCR V $\beta$ repertoire observed in SLE patients at initial diagnosis. $M$ mean value (derived from controls sample), $S D$ standard deviation. females) undergoing minor surgery at the First and Second Department of Surgery at "Aghia Sophia" Children's Hospital were included as controls. Taking into account that several germ line polymorphisms of the TCR V $\beta$ genes have been described in different ethnicities [22,23], this study was restricted to children of Greek origin in order to include an ethnically homogeneous population. A standardized interview was held with parents of all children.

\section{Ethical approval}

The study was approved by the Ethical Committee of the "Aghia Sophia" Children's Hospital and participants were included in the study only after informed consent was obtained from their parents or guardians.

\section{Methodology}

Blood (4 $\mathrm{ml}$ in EDTA tube and $3 \mathrm{ml}$ serum) was taken from all participants for investigations, including full blood count, serum immunoglobulin levels assessment by nephelometry and screening for autoantibodies by indirect immune-fluorescence (ANA, anti-dsDNA, ICA), as well as lymphocyte subpopulation immunophenotyping by flow cytometry.

\section{Flow cytometry}

$\mathrm{CD} 4+\mathrm{TCR} V \beta$ repertoire was analyzed using threecolor flow cytometry with the IOTest Beta Mark TCR Repertoire Kit (Beckmann Coulter, Marseille, France), which consists of fluorochrome conjugated monoclonal antibodies that identify 24 TCR V $\beta$ subfamilies, covering about the $70 \%$ of the normal human CD4+ T cells. Since at the time of the study initiation, only three-color flow cytometry was in practice, and in order to assess the results with the same method, no changes in methodology were undertaken. For that reason only the CD4+ TCR $\mathrm{V} \beta$ repertoire and not the CD8+ one was assessed. Peripheral blood samples were collected in tubes containing anticoagulant (EDTA) and were stained within 2 hours. $100 \mu \mathrm{l}$ of blood was incubated for 20 minutes, at room temperature with $20 \mu \mathrm{l}$ of a mixture of three distinct anti$\mathrm{V} \beta$ monoclonal antibodies and $10 \mu \mathrm{l}$ of anti-CD4-PC5 monoclonal antibody (MoAb). Erythrocytes were lysed by 

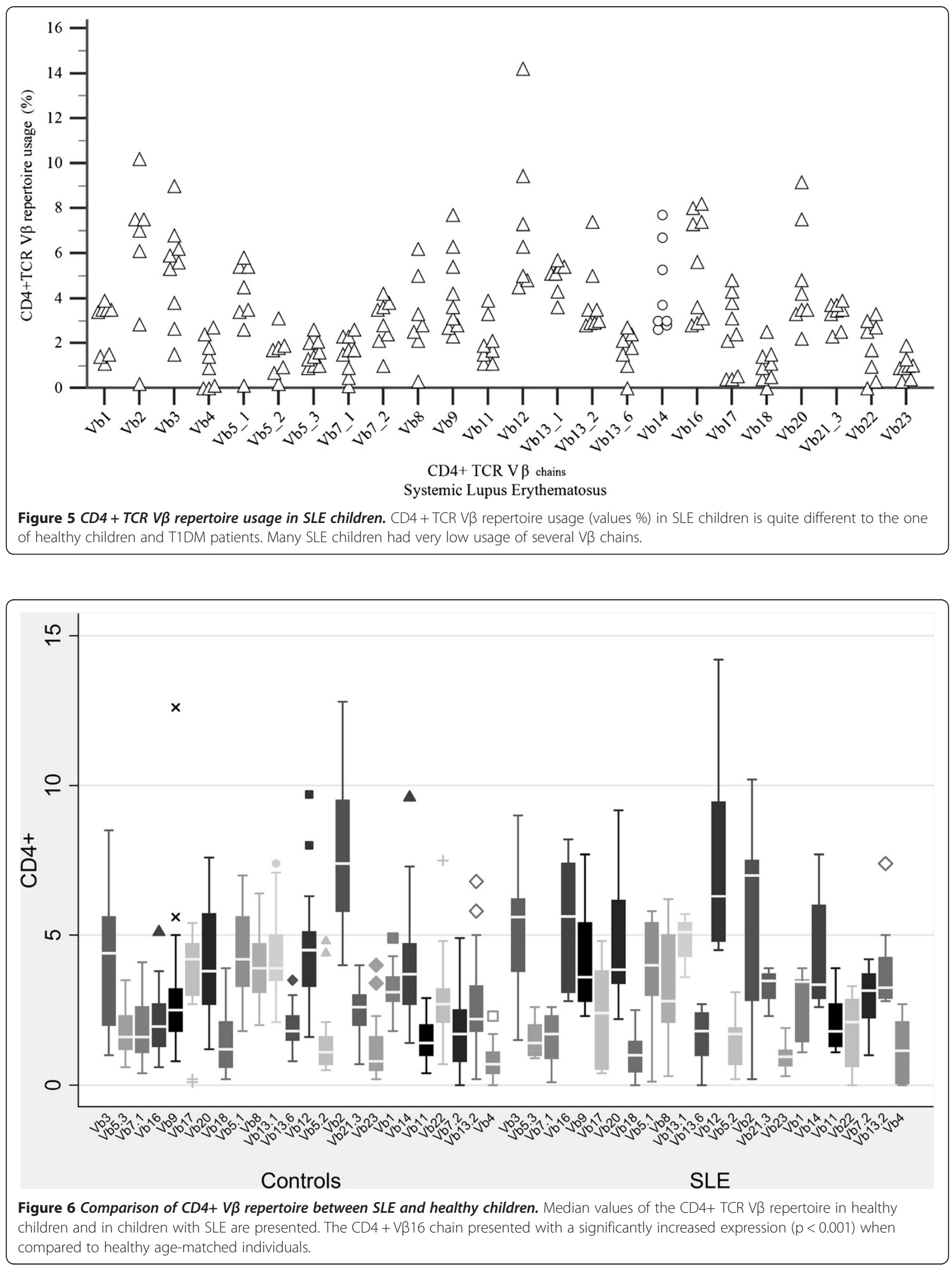


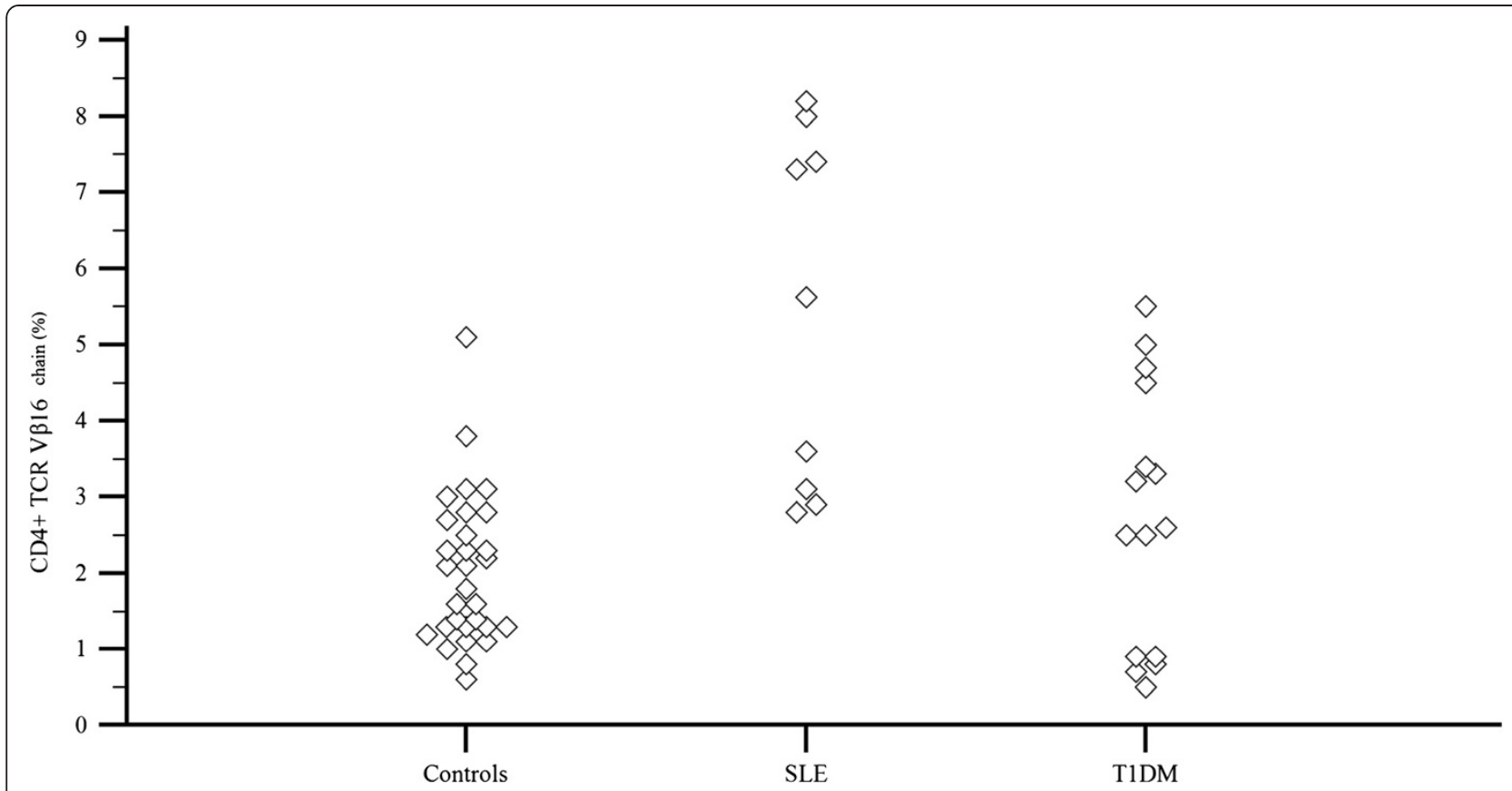

Figure 7 Comparison of $C D 4+V \beta 16$ chain values among the 3 groups of children studied. Values (\%) of the CD $4+V \beta 16$ chain are higher in the majority of SLE children in comparison to controls.

$\mathrm{NH}_{4} \mathrm{Cl}$ solution. At least $10.000 \mathrm{CD} 4+$ lymphocytes were collected for analysis. CD4+ lymphocytes were gated using forward scatter, side scatter and FL4 fluorescence; whereas $\mathrm{V} \beta$ repertoire analysis used two additional fluorescence channels (FL1 and FL2).

Data acquisition was performed initially on an EPICS XL (Beckman Coulter) flow cytometer and, later on, on an FC-500 (Beckman Coulter), instrument. Listmode analysis was performed using the CXP software.

Lymphocyte subpopulations tested were: 1) $\mathrm{CD} 3+\mathrm{T}$ cells, 2) helper $\mathrm{T}$ cells $(\mathrm{CD} 3+\mathrm{CD} 4+), 3)$ cytotoxic $\mathrm{T}$ cells $(\mathrm{CD} 3+\mathrm{CD} 8+), 4)$ natural killer cells (CD56+) and 5) B lymphocytes (CD19+). Moreover, the $\alpha \beta$ and $\gamma \delta$ expression on T cells, the expression of CD69+ and HLA-DR + on $\mathrm{T}$ cells as activation markers and the expression of CD5+ on CD19+ B cells were studied.

\section{Statistical analysis}

Statistical analysis among three age groups of the healthy individuals included in the study was performed in order to detect possible skewing among them. Age was transformed to categorical variables, thus constructing three age groups: 18 months $-4^{11 / 12}$ years $(\mathrm{n}=12), 5-9^{11 / 12}$ years $(\mathrm{n}=10)$ and $\geq 10$ years $(n=9)$. The reason for this transformation was to reveal a possible difference in $\mathrm{V} \beta$ repertoire usage among specific age groups that roughly reflect the stages of child development and immune system maturation. $\mathrm{V} \beta$ repertoire expression variables are described as median and interquartile range IQR (75th-25th percentile) due to the small sample size and to their non-normal distribution. For the same reason, non parametric statistics were used; Mann-Whitney U statistic was used for the comparison of the aforementioned variables between two age subgroups and Kruskal-Wallis rank test when comparing the same variables among the three age subgroups of the study. All tests were two-sided at a significance level of $\mathrm{p}<0.5$. Data were analyzed using STATA ${ }^{\mathrm{m}}$ (Version 9.0, Stata Corporation, College Station, TX 77845, USA).

To assess the possible differences of CD $4+$ TCR V $\beta$ repertoire expression, pediatric patients with newly diagnosed SLE and T1DM were compared with healthy agematched controls. Due to the small subgroup sizes of SLE and T1DM ( $\mathrm{n}=9, \mathrm{n}=15$ respectively), median and IQR $\left(75^{\text {th }}-25^{\text {th }}\right.$ percentile) were used to describe the continuous variables. In addition, nonparametric statistical analysis (Mann-Whitney U) was used to test for any significant differences between the subgroups. Due to the multiple comparisons $(\mathrm{n}=24)$, Bonferroni adjustment was performed in order to correct for inflation in type I error, setting the significance level from $\mathrm{p}<0.05$ to $<0.0021(=0.05 / 24)$. Statistical analysis was also adjusted to a $\mathrm{CV}$ of $20 \%$, which could characterize the results of $V \beta$ chains with rare expression. The significant difference that was found between controls and T1DM patients in $\mathrm{V} \beta 4$ chain was also present when using Student's t-test for the comparison. Although t-test is a parametric statistic and less powerful in our case due to the small number of patients, it allowed us to perform 
new hypothetical comparisons between the aforementioned groups in order to verify that the comparisons would remain significant even after increasing the mean value in the control group by $20 \%$ and decreasing the mean value in the T1DM group (for V $\beta 4$ chain) by $20 \%$.

\section{Abbreviations}

TCR: T Cell receptor; T1DM: Type 1 diabetes mellitus; SLE: Systemic Lupus Erythematosus; IQR: Interquantile range; CV: Coefficient of variation.

\section{Competing interests}

We disclose any financial competing interests. There are no non-financial competing interests to declare in relation to this manuscript.

\section{Authors' contributions}

FT carried out the study (collection of patients and controls, conduction of flow cytometric analysis and autoantibody screening) and has written the manuscript. MK has significantly contributed in the conception and design, the acquisition of data, the analysis and interpretation of data as well as in the drafting the article and in revising it critically for important intellectual content. She has also significantly contributed in the final approval of the version to be published. MT contributed in the analysis and interpretation of the data and revised the manuscript. CM has significantly contributed in the acquisition of data and the analysis and interpretation of data as well as in the drafting the article and revising it critically. More specifically due to his high qualifications in statistical analysis and interpretation he has contributed in the interpretation and presentation of the important findings of the study. EP has personally conducted the measurement of serum immunoglobulin levels and the assessment and screening for autoantibodies and she has contributed to the interpretation of data. GC revised the manuscript critically for important intellectual content. CKG contributed in the interpretation of the collected data and the preparation of the manuscript. Together with MK, she had the main contribution in the drafting of the article and in revising it critically for important intellectual content. She has also significantly contributed in the final approval of the version to be published. All authors read and approved the final manuscript.

\section{Authors' information}

$\mathrm{FT}$ is the PhD candidate, who has conducted the study under the supervision of Dr. Maria Kanariou, the Director of the Department of Immunology \& Histocompatibility, "Aghia Sophia" Children's Hospital, Greece and the help of the members of the Department of Immunology \& Histocompatibility. She holds master degree in "Molecular Medicine" (supervisor of the two-year training in basic research methodology is Professor Nikolaos Anagnou). She is Pediatrician and is currently Consultant at the $3^{\text {rd }}$ Department of Pediatrics' Clinics of "Attikon" University Hospital.

MK is the Director of the Department of Immunology \& Histocompatibility, Specific Center \& Referral Center for Primary Immunodeficiencies - Paediatric Immunology, "Aghia Sophia" Children's Hospital, Greece where all laboratory measurements have been conducted under her supervision.

MT is a Medical Biopathologist with over a decade of experience in Flow Cytometry. She is currently responsible for the Flow Cytometry and Cell Culture Laboratories of the Department of Immunology \& Histocompatibility, Specific Center \& Referral Center for Primary Immunodeficiencies - Paediatric Immunology, "Aghia Sophia" Children's Hospital.

CM is GP. Consultant at Hospital of Kimi, Greece and holds a master degree in biostatistics and PhD diploma in epidemiology. He also has many publications in several studies in which he contributed as a biostatistician.

EP is also a staff member of the Department of Immunology \& Histocompatibility, "Aghia Sophia" Children's Hospital, Greece. GC is the Medical Director of the First Department of Pediatrics and the Division of Endocrinology, Diabetes and Metabolism, of the National Kapodistrian University of Athens, "Aghia Sophia" Children's Hospital, Greece. CKG is the supervisor of Mrs Tzifi' PhD thesis and the scientific supervisor of the Diabetes Center, where the type 1 diabetes patients are followed. She is Associate Professor for Pediatric Endocrinology and Juvenile Diabetology in the First Department of Pediatrics and the Division of Endocrinology, Diabetes and Metabolism, of the Medical School of the National Kapodistrian University of Athens, "Aghia Sophia" Children's Hospital, Greece.

\section{Acknowledgments}

The authors are grateful to Professor Dr. P.G. Vlachoyiannopoulos for his constructive suggestions, to Drs Efi Vrachnou, Manolis Liatsis, and Nektaria Papadopoulou, as well as to Mrs Virginia Polaki for their valuable contribution. We also thank Drs. Theodoros Dolatzas and Georgios Christopoulos-Geroulanos, for providing access to their patients.

\section{Author details}

${ }^{1}$ First Department of Pediatrics, Division of Endocrinology, Diabetes and Metabolism, National Kapodistrian University of Athens, "Aghia Sophia" Children's Hospital, Thivon \& Papadiamantopoulou street, 11527 Athens, Greece. ${ }^{2}$ Department of Immunology \& Histocompatibility, Specific Center \& Referral Center for Primary Immunodeficiencies - Paediatric Immunology, "Aghia Sophia" Children's Hospital, Athens, Greece. ${ }^{3}$ Internal Medicine Department, Kimi General Hospital "G. Papanicolaou", Kimi, Greece.

Received: 18 March 2013 Accepted: 31 July 2013

Published: 3 August 2013

\section{References}

1. Hewagama A, Richardson B: The genetics and epigenetics of autoimmune diseases. J Autoimmun 2009, 33:3-11.

2. Kivity S, Agmon-Levin N, Blank M, Shoenfeld Y: Infections and autoimmunity-friends or foes? Trends Immunol 2009, 30:409-414.

3. Shelly S, Boaz M, Orbach H: Prolactin and autoimmunity. Autoimmun Rev $2012,11: 465-470$

4. Zhang J, Wei W, Wang C: Effects of psychological interventions for patients with systemic lupus erythematosus: a systematic review and meta-analysis. Lupus 2012, 21:1077-1087.

5. Gold DP: TCR V, gene usage in autoimmunity. Curr Opin in Immun 1994, 6:907-912.

6. Okajima M, Wada T, Nishida M, Yokoyama T, Nakayama Y, Hashida Y, Shibata F, Tone Y, Ishizaki A, Shimizu M, Saito T, Ohta K, Toma T, Yachie A: Analysis of T cell receptor Vbeta diversity in peripheral CD4 and CD8 T lymphocytes in patients with autoimmune thyroid diseases. Clin Exp Immunol 2009, 155:166-172.

7. Brogan PA, Shah V, Bagga A, Klein N, Dillon MJ: T cell Vbeta repertoires in childhood vasculitides. Clin Exp Immunol 2003, 131:517-527.

8. Long SA, Khalili J, Ashe J, Berenson R, Ferrand C, Bonyhadi M: Standardized analysis for the quantification of Vbeta CDR3 T-cell receptor diversity. J Immunol Methods 2006, 20:100-113.

9. Memon SA, Sportès C, Flomerfelt FA, Gress RE, Hakim FT: Quantitative analysis of $\mathrm{T}$ cell receptor diversity in clinical samples of human peripheral blood. J Immunol Methods 2012, 375:84-92.

10. Van den Beemd R, Boor PP, van Lochem EG, Hop WC, Langerak AW, Wolvers-Tettero IL, Hooijkaas $\mathrm{H}$, van Dongen JJ: Flow cytometric analysis of the Vbeta repertoire in healthy controls. Cytometry 2000, 1:336-345.

11. McLean-Tooke A, Barge D, Spickett GP, Gennery AR: T cell receptor Vbeta repertoire of $\mathrm{T}$ lymphocytes and T regulatory cells by flow cytometric analysis in healthy children. Clin Exp Immunol 2007, 151:190-198.

12. Wong S, Wen L, Hibberd M, Millward A, Demaine A: Analysis of the peripheral T-cell receptor $\mathrm{V}$ beta repertoire in newly diagnosed patients with type I diabetes. Autoimmunity 1994, 18:77-83.

13. Luppi P, Zanone MM, Hyoty H, Rudert WA, Haluszczak C, Alexander AM, Bertera S, Becker D, Trucco M: Restricted TCR, V beta gene expression and enterovirus infection in type I diabetes: a pilot study. Diabetologia 2000, 43:1484-1497.

14. Fraser PA, Lu LY, DeCeulaer K, Schur PH, Fici D, Awdeh Z, Ding WZ, Levitan E, Lew R, Uko G, Gonzalez C: CD4 TCRBV CDR3 analysis in prevalent SLE cases from two ethnic groups. Lupus 1999, 8:311-319.

15. Luo W, Ma L, Wen Q, Wang N, Zhou MQ, Wang XN: Analysis of the interindividual conservation of $\mathrm{T}$ cell receptor alpha- and beta-chain variable regions gene in the peripheral blood of patients with systemic lupus erythematosus. Clin Exp Immunol 2008, 154:316-324.

16. De Inocencio J, Choi E, Glass DN, Hirsch R: T cell receptor repertoire differences between African Americans and Caucasians associated with polymorphism of the TCRBV3S1 (V beta 3.1) gene. J Immunol 1995, 154:4836-41.

17. Wedderburn $L R$, Patel A, Varsani $H$, Woo P: The developing human immune system: T-cell receptor repertoire of children and young adults 
shows a wide discrepancy in the frequency of persistent oligoclonal T-cell expansions. Immunology 2001, 102:301-9.

18. Malhotra U, Spielman R, Concannon P: Variability in T cell receptor $V$ beta gene usage in human peripheral blood lymphocytes. Studies of identical twins, siblings, and insulin-dependent diabetes mellitus patients. Immunol 1992, 1:1802-1808.

19. Fozza C, Zoledzieska M, Pitzalis M, Simula MP, Galleu A, Contini S, Bonfigli S, Cucca F, Longinotti M: TCRBV20S1 polymorphism does not influence the susceptibility to type 1 diabetes and multiple sclerosis in the Sardinian population. Immunogenetics 2012, 64:153-154.

20. Yuling H, Ruijing X, Xiang J, Yanping J, Lang C, Li L, Dingping Y, Xinti T, Jingyi L, Zhiqing T, Yongyi B, Bing $X$, Xinxing W, Youxin J, Fox DA, Lundy SK, Guohua D, Jinquan T: CD19+CD5+ B cells in primary lgA nephropathy. J Am Soc Nephrol 2008, 19:2130-2139.

21. De Filippo G, Pozzi N, Cosentini E, Cavalcanti M, Carel JC, Tamasi S, Franzese A, Pignata C: Increased CD5 + CD19+ B lymphocytes at the onset of type 1 diabetes in children. Acta Diabetol 1997, 34:271-274.

22. Mackelprang R, Carlson CS, Subrahmanyan L, Livingston RJ, Eberle MA, Nickerson DA: Sequence variation in the human T-cell receptor loci. Immunol Rev 2002, 190:26-39.

23. Bonfigli S, Fozza C, Contini S, Buzzetti R, Cucca F, Longinotti M: High frequency of the TCRBV20S1 null allele in the Sardinian population. Hum Immunol 2007, 68:426-429.

Cite this article as: Tzifi et al:: Flow cytometric analysis of the CD4+ TCR $V \beta$ repertoire in the peripheral blood of children with type 1 diabetes mellitus, systemic lupus erythematosus and age-matched healthy controls. BMC Immunology 2013 14:33.

\section{Submit your next manuscript to BioMed Central and take full advantage of:}

- Convenient online submission

- Thorough peer review

- No space constraints or color figure charges

- Immediate publication on acceptance

- Inclusion in PubMed, CAS, Scopus and Google Scholar

- Research which is freely available for redistribution 